\title{
Why are you here? Needs analysis of an interprofessional health-education graduate degree program
}

This article was published in the following Dove Press journal:

Advances in Medical Education and Practice

II April 2014

Number of times this article has been viewed

\author{
Christian Cable ${ }^{1,2}$ \\ Mary Knab ${ }^{3,4}$ \\ Kum Ying Tham ${ }^{5,6}$ \\ Deborah D Navedo ${ }^{3}$ \\ Elizabeth Armstrong ${ }^{3,7,8}$
}

'Scott and White Healthcare, Temple,

${ }^{2}$ Texas A\&M University Health

Science Center, TAMHSC College

of Medicine, Bryan, TX, ${ }^{3} \mathrm{MGH}$

Institute of Health Professions,

${ }^{4}$ Physical and Occupational Therapy

Services Department, Massachusetts

General Hospital, Boston, MA,

USA; ${ }^{5}$ Emergency Department,

Tan Tock Seng Hospital, 'ㄴee Kong

Chian School of Medicine, Nanyang

Technological University, Singapore;

${ }^{7}$ Harvard Macy Institute, ${ }^{8}$ Department of Pediatrics, Harvard Medical School, Boston, MA, USA
Correspondence: Christian Cable Scott and White Healthcare,

240I South 3Ist Street, Temple,

TX 76508, USA

Tel + I 254724 |713

Fax + I 2547244079

Email ccable@sw.org

\begin{abstract}
Little is known about the nature of faculty development that is needed to meet calls for a focus on quality and safety with particular attention to the power of interprofessional collaborative practice. Through grounded-theory methodology, the authors describe the motivation and needs of 20 educator/clinicians in multiple disciplines who chose to enroll in an explicitly interprofessional master's program in health profession education. The results, derived from axial coding described by Strauss and Corbin, revealed that faculty pursue such postprofessional master's degrees out of a desire to be better prepared for their roles as educators. A hybrid-delivery model on campus and online provided access to graduate degrees while protecting the ability of participants to remain in current positions. The added benefit of a community of practice related to evidence-based and innovative models of education was valued by participants. Authentic, project-based learning and assessment supported their advancement in home institutions and systems. The experience was described by participants as a disruptive innovation that helped them attain their goal of leadership in health profession education.
\end{abstract}

Keywords: health education

\section{Introduction}

Few would dispute the assertion that health profession education is changing. The nature and implications of this change are more open to interpretation. Increased focus on patient safety, quality of health care, and the power of collaborative practice would be considered common ground. ${ }^{1}$ It is also accepted that generations of health professionals were not trained with these foci at the fore. Therefore, the need for highquality interprofessional faculty development has risen in prominence. ${ }^{2}$ This need can be satisfied with local offerings, national conferences, or e-learning resources. However, a cohort of key faculty desires advanced training in medical education in either residential, online, or hybrid programs. Little is known about the motivation and needs of this cadre of faculty. The purpose of this study is to construct a theory concerning the motivation and needs of faculty pursuing master's degree training in health profession education, grounded in the lived experiences of the partners-indevelopment class of a nascent program.

\section{Background}

Recent calls for reform in health profession education have extolled the necessity for faculty development. If this education is to meet the challenges posed by a rapidly evolving health care system, then the trainers must be trained. The Carnegie Foundation's centenary report on medical education and the Lancet 
Commission's report on health care education at large each call for sweeping changes by emphasizing the interrelatedness and systems orientation of health care. Faculty development to drive these changes is prescribed by each body. ${ }^{3,4}$ However, the nature of such faculty development is seldom specified, and the perspective of faculty desiring to participate has not been heard. Little is known about master's degree students in general, and even less about health professionals pursuing postprofessional master's training in education.

The literature's landscape concerning this topic is largely barren, but some scholars have left helpful landmarks. Stenfors-Hayes et al studied volunteer respondents in a mandatory course about teaching and learning at a large academic medical center. ${ }^{5}$ Using semistructured interviews and qualitative data-analysis methods, they identified self-efficacy as a major theme concerning postprofessional faculty development in education. Those with positive views displayed intrinsic motivation. Barriers to professional development were perceived at an institutional level, and centered on questions of extrinsic motivation. In contrast to the setting of an academic medical center, Curran et al reported the attitudes of health professionals in rural Canada. ${ }^{6}$ Continuing education was identified as a means to address the professional isolation felt by rural practitioners. Geographic isolation and poor telecommunications and technological infrastructure were identified as major barriers to more efficient implementation of continuing faculty development. Distance learning and asynchronous delivery were proposed as solutions if technical considerations could be addressed. Richardson presented a detailed account of occupational therapists who participated in a postprofessional master's program. ${ }^{7}$ This was a distance-learning degree focused on clinical practice and investigation. Participants described a developmental process in learning, the value of an online community, and the positive and negative influences of online pedagogy. In a general study of master's degree students, Walsh and Tucker found the motivation of most participants centered on a desire to upgrade workplace skills and to expand career flexibility. ${ }^{8}$ Nurses pursued postprofessional master's training to enhance leadership skills and to qualify for positions of greater responsibility. ${ }^{9}$

The aforementioned surveys are helpful, but much remains unknown. Studies that dealt with participant motivation and needs were either not focused on teaching or did not occur at the master's level. Interprofessional training at this level was not described. As postprofessional master's degrees in health profession education proliferate, the voice of faculty desiring to participate has not yet been heard. Qualitative methods are especially well suited to address this gap. Qualitative analyses in general and grounded theory specifically represent an inductive approach, where a theory is generated from the experience of the subjects. Qualitative methods are gaining in prominence in the literature regarding needs assessment for advanced faculty development. ${ }^{10}$ Aherne et al state that "... needs assessment studies are inevitably value expressions and social constructions of the planners and the stakeholder communities they engage."'11 This subjectivist orientation to needs assessment lends itself to focus-group methodology. Tipping touts the constant comparative approach of focus groups and their ability to reveal ambiguous topics as arguments in favor of this method for needs assessment. ${ }^{12}$

Without preconceived theory, this study asked a cohort of master's students in health professions education, "Why are you here and what are your needs?" In addition, "What issues in your professional career are you trying to address?"

\section{Materials and methods}

In 2012, we convened a live focus group of the 20 initial participants in an interprofessional master's degree program in health profession education. The sample was theory-based to represent those that had committed the resources to proceed with an extended course of study. The MGH (Massachusetts General Hospital) Institute of Health Professions Institutional Review Board granted exemption to this study, and all scholars consented to participate.

The degree content was delivered by a hybrid model, and all participants had met previously in live or distancelearning classes. Seventeen physicians, one physical therapist, one clinical psychologist, and one advanced-practice nurse comprised the group. Nine participants were from North America, and eleven were from Singapore. Women $(n=9)$ and men were equally represented. Two experienced nonparticipant moderators posed open-ended questions concerning motivation for pursuing advanced training in education. The approach to grounded-theory analysis and interpretation described by Strauss and Corbin was used. ${ }^{13}$ All responses were transcribed and independently reviewed by $\mathrm{CC}$ and $\mathrm{MK}$ to generate open codes. A central phenomenon was identified to inform axial coding in causal conditions, strategies, contextual and intervening conditions, and consequences vis-à-vis the central theme. The resulting theory was elaborated by selective coding and presented to the participants for confirmation and further refinement in a constant comparative approach. 


\section{Results}

Table 1 presents a representation of axial coding and the resultant theory. The following is a discursive presentation of the grounded theory. The voice is that of an amalgam of the participants. This is not the story of one, but faithfully represents the experience of the cohort. The narrative relates classic axial coding categories described by Strauss and Corbin. ${ }^{13}$

\section{Central phenomenon}

"I want to be a leader in health professions education within the next 10 years. I hired this program to help me achieve that goal."

\section{Causal conditions}

"I've always been interested in teaching and learning. I taught how I was taught or sometimes how I wished I had been taught, preparing discussions or clinical rotation schedules on nights and weekends while maintaining a busy clinical practice of my own. Gradually, I realized that this was shifting from hobby to passion. My bosses recognized that too, and more responsibility came. The problem was that I was poorly prepared: I'd been taught to be a good clinician, and by mimicking those who had taught me well, a good teacher. Being a good teacher was not the same as leading education; I had reached the boundaries of mimicry and intuition, but I was still not an educator. Was there evidence, a science, upon which to base decisions related to my teaching, curriculum development, and program evaluation? I was curious, desirous of a challenge, and ignorant. My colleagues were sympathetic, but somehow thought me strange for taking this much interest in education. I felt isolated, and I needed more."

\section{Contextual and intervening conditions}

"This happened mid-career for me. I had become comfortable with clinical practice, and was asked to do more than frontline teaching with students at many levels. I needed help to build curriculum, improve the way our students and residents are taught, increase interprofessional collaboration, and contribute to a culture of continuous quality improvement centered on patient safety. It seemed like our very system of education needed to be reinforced or reimagined. I started to view health professions education as a young field, perhaps a frontier with room to grow. Certainly it was a less developed career path than either clinical practice or research. My participation started at a time when my institution, like many others, was undergoing financial constriction. The administrators

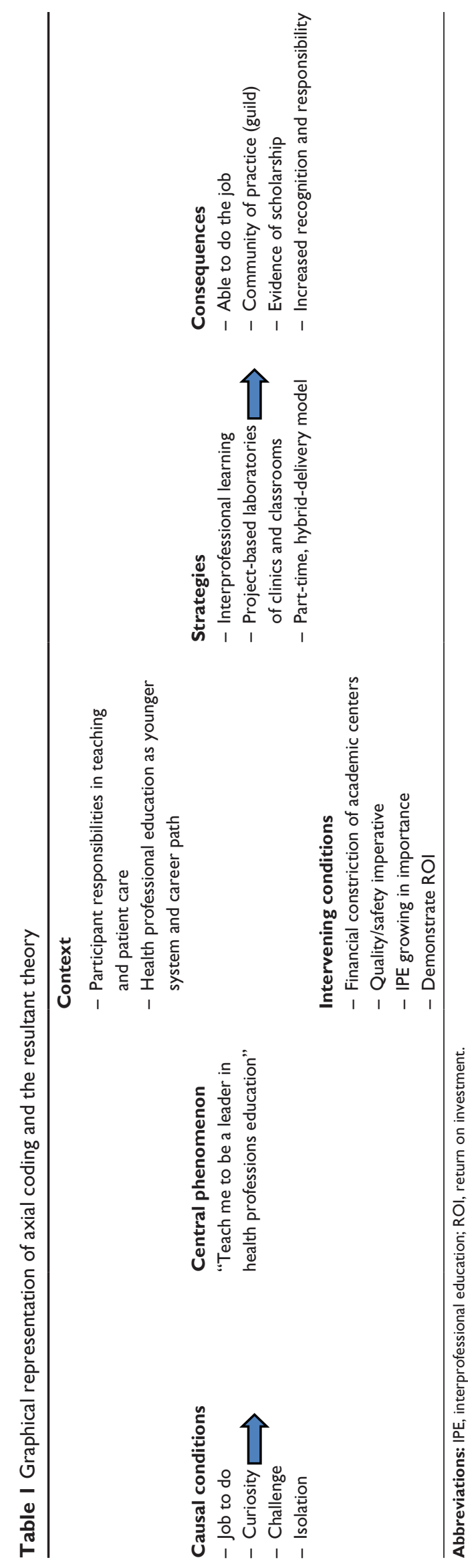


at my hospital were willing to invest in education, but they wanted demonstrable return on that investment. The synergy between education and quality/safety was a driving reason for their patronage. The imperative to improve teaching effectiveness also helped."

\section{Strategies}

"There was this first eureka moment when I realized that there was a science to better teaching embedded in a program that led to a master's degree. This master's program worked for me on many levels. The hybrid-delivery model balanced live and distance learning in a way that enabled me to participate. I would not have left my patients or uprooted my family for 2 years of full-time study. But over the span of 3 years, I could carefully choose 8 weeks to be in residence. We learned theories of adult learning and the evidence that underpinned them. More importantly, the evaluation system was project-based. Each course of study required an authentic educational project to be implemented at home. The clinic and classroom served as educational laboratories to try out the concepts we were learning. As has evolved in this telling of my story, there was a second eureka moment when I realized that there were others like me. Over time, I began to refer to the work 'we' were doing as a community of learners engaged in exploring the scientific underpinnings of and innovative approaches to health professions education. This energized me, and helped my own work evolve. The interprofessional nature of the learning environment was essential. I came to see the growing rationale for training that reflects the systems nature of health care. This was the first time that I had trained in an environment where silos were purposefully deconstructed."

\section{Consequences}

"As a result of this program, I see the beginnings of my transformation from amateur (one who loves) to professional (one who loves and professes). I haven't lost curiosity or desire for a challenge; rather, these impulses have matured. More importantly, I have found a community of practice: a guild, a fellowship founded on curiosity and courage. There are others who share this interest, language, and aspiration concerning education, and courage to be change agents. I have become more competent to serve the local needs of my institution, and several of the projects from the course are blossoming into scholarship appropriate for broader dissemination. I better understand how to teach and learn in the interprofessional environment, and am better positioned for leadership in health professions education. This course of advanced study has done what I hired it to do."

\section{Discussion}

In describing their pursuits of advanced training in education, our participants began and ended with the language of Wessel and Christensen's disruptive innovation. ${ }^{14}$ The core attribute of a disruptive innovation is the ability to meet a need on a broader scale. Digital music disrupted compact discs despite the audiophiles' rebuttal of lower fidelity. Accessibility actually expanded the market. Health profession educators have a need to prepare students and themselves for a clinical and educational environment that emphasizes outcome over process. Many address this need the way scholars always have - by studying more. But time and money can limit deep participation. These health professionals were active teachers and clinicians. That is a powerful basis for developmental teaching, but is practically limiting for their own postprofessional development.

While global shifts in health care emphasis supplied incentives for academic centers to provide financial support, these faculty brought intrinsic motivation to learn and advance toward professional status as educators. ${ }^{2}$ Time, however, is a less fungible resource than money. Borrowing from the structure of an executive master of business administration, this program and others like it address the learner's need to remain actively employed. Online or hybrid programs provide enough quality while expanding accessibility - a disruptive innovation. An argument can even be made that part-time development in education is superior for an advanced learner. The learning laboratory metaphor of clinic or classroom that resonated with our cohort aligns with many streams of adult learning theory. ${ }^{15,16}$ Project-based assessment also improves in validity when projects are authentic tasks required to solve existing problems. ${ }^{17,18}$

We found that our participants discovered an unmet need they had not identified prospectively. They craved and found a community of like-minded individuals. In describing this phenomenon, participants' language varied from "joining a guild" to "being cool." We did not know that we needed digital music until others invented and Steve Jobs perfected it. Community is a key component of professional formation, and like Richardson, ${ }^{7}$ we demonstrated that it is attainable in a part-time program. The live-seminar components of this program reinforced connections made in an online environment and fostered future networking.

Our findings, in fact, reveal that participants found not just any community, but a community of practice (CoP), 
as described by Wenger, ${ }^{19,20}$ and Wenger and Snyder. ${ }^{21}$ In contrast to other informal networks or formal work groups, CoP members self-select in order to build and exchange knowledge, solve problems, or develop competence. As such, a CoP provides a conceptual framework for the consequences portion of this study's grounded theory with its elements of ability to do one's job, enhance scholarship, and assume increased responsibility. CoPs are held together by "passion, commitment and identification with the group's expertise," 21 very much evident in participants' descriptions of what they found by engaging in the masters in health profession education program.

That intrinsic needs were met by master's training in education was validated by the voice of the participants. However, could such a program as this satisfy extrinsic expectations? DeVaro and Waldman ${ }^{22}$ describe a master's degree as an important signal in the likelihood of future promotion. Ball et $\mathrm{al}^{23}$ found that distance-learning master's degrees were favorably received by prospective employers of physical therapists if the subject matter was education, but not if basic or clinical science. In another study, allied health professionals enrolled in a postprofessional master's program identified the business and education tracks as more valuable to furthering their careers than the clinical track, and their employers reported enhanced job performance. ${ }^{24}$ We posit that master's level education offered in a distance-learning format is an acceptable way for health professions educators to advance in the profession.

The major limitation of this work is the nature of the cohort studied. These were ambitious and accomplished educators who sought out a rigorous program at significant personal expense. Does this cohort represent the majority of teaching faculty in the health professions? Certainly not. However, a few faculty members from every institution are represented here in archetype, and these are the same types of learner-teachers that will bring innovation back to their home institutions. A prominent educator at the turn of the last century described the significant leverage brought to bear in work and education by a talented minority. Du Bois thought that a small group could have a big impact. ${ }^{25}$ Our view of the faculty represented in this study is that they represent Du Bois's "talented tenth," and that like-minded individuals are present in every health care-education environment. ${ }^{25}$

\section{Conclusion}

This needs assessment revealed that faculty pursue postprofessional master's degrees in health profession education out of a desire to be better prepared for their educator roles and a thirst for the science upon which teaching practice is based. Through it, they find a community of professional educators - a community of practice. They are enabled by the access that hybrid-delivery models afford, and authentic, project-based learning and assessment support their advancement in home institutions and systems. They described the experience as a disruptive innovation that met known and discovered needs.

\section{Acknowledgments}

The authors wish to thank June Lubowinski, MLS, MA for literature review throughout the project, Lynne Foord, DPT, PhD for cofacilitation of the focus-group session, and Glen Cryer for assistance with manuscript preparation and submission.

\section{Disclosure}

The authors report no conflicts of interest in this work.

\section{References}

1. Christensen CM, Grossman JH, Hwang J. The Innovator's Prescription: A Disruptive Solution for Health Care. New York: McGraw Hill; 2009.

2. Interprofessional Education Collaborative Expert Panel. Core Competencies for Interprofessional Collaborative Practice: Report of an Expert Panel. Washington: Interprofessional Education Collaborative; 2011.

3. Cooke M, Irby DM, O'Brien BC, Schulman LS. Educating Physicians. A Call for Reform of Medical School and Residency. San Francisco: Jossey-Bass; 2010.

4. Frenk J, Chen C, Bhutta ZA, et al. Health professionals for a new century: transforming education to strengthen health systems in an interdependent world. Lancet. 2010;376:1923-1958.

5. Stenfors-Hayes T, Weurlander M, Dahlgren L, Hult H. Medical teachers professional development - perceived barriers and opportunities. Teach Higher Educ. 2010;15:399-408.

6. Curran VR, Fleet L, Kirby F. Factors influencing rural health care professionals' access to continuing professional education. Aust J Rural Health. 2006;14:51-55.

7. Richardson P. Student development in an online post-professional master's program. Occup Ther Health Care. 2004;18:107-116.

8. Walsh S, Tucker K. The perspectives of students undertaking masters' degrees by coursework on career development learning. Aust J Career Dev. 2011;20:42-43.

9. Drennan J. Masters in nursing degrees: an evaluation of management and leadership outcomes using a retrospective pre-test design. $J$ Nurs Manag. 2012;20:102-112.

10. Hauer J, Quill T. Educational needs assessment, development of learning objectives, and choosing a teaching approach. J Palliat Med. 2011;14:503-508.

11. Aherne M, Lamble W, Davis P. Continuing medical education, needs assessment, and program development: theoretical constructs. J Contin Educ Health Prof. 2001;21:6-14.

12. Tipping J. Focus groups: a method of needs assessment. J Contin Educ Health Prof. 1998;18:150-154.

13. Strauss A, Corbin J. Basics of Qualitative Research: Grounded Theory Procedures and Techniques. Newbury Park (CA): Sage; 1990.

14. Wessel M, Christensen C. Surviving disruption. Harv Bus Rev. 2012;90:56-65. 
15. Kolb DA. Experiential Learning: Experience as the Source of Learning and Development. Englewood Cliffs (NJ): Prentice-Hall; 1984.

16. Arseneau R, Rodenburg D. The developmental perspective: cultivating ways of thinking. In: Pratt DD. Five Perspectives on Teaching in Adult and Higher Education. Malabar (FL): Krieger; 1998.

17. Newmann F, Marks H, Gamoran A. Authentic pedagogy and student performance. Am J Educ. 1996;104:280-312.

18. Wiggins GP. Assessing Student Performance: Exploring the Purpose and Limits of Testing. San Francisco: Jossey-Bass; 1993.

19. Wenger E. Communities of Practice: Learning, Meaning and Identity. New York: Cambridge University Press; 1998.

20. Wenger E. Communities of practice and social learning systems. Organization. 2000;7:225-246.

21. Wenger E, Snyder W. Communities of practice: the organizational frontier. Harv Bus Rev. 2000;78:139-146.
22. DeVaro J, Waldman M. The signaling role of promotions: further theory and empirical evidence. J Labor Econ. 2012;30:91-147.

23. Ball A, Rosenberg A, Gandy J. Marketability of physical therapists with a postprofessional degree earned through distance education. J Phys Ther Educ. 2002;16:76-82.

24. Murray C, Judd D, Snyder P. Evaluation of a post-professional master's program in allied health. $J$ Allied Health. 2001;30:223-228.

25. Du Bois WEB. The talented tenth. In: Du Bois WEB. The Negro Problem: A Series of Articles by Representative Negroes of Today. New York: Gilder Lehrman Center for the Study of Slavery, Resistance and Abolition; 1903. Available from: http://www.yale.edu/glc/ archive/1148.htm. Accessed March 4, 2013.

\section{Publish your work in this journal}

Advances in Medical Education and Practice is an international, peerreviewed, open access journal that aims to present and publish research on Medical Education covering medical, dental, nursing and allied health care professional education. The journal covers undergraduate education, postgraduate training and continuing medical education including emerging trends and innovative models linking education, research, and health care services. The manuscript management system is completely online and includes a very quick and fair peer-review system. Visit http://www.dovepress.com/testimonials.php to read rea quotes from published authors.

Submit your manuscript here: http://www.dovepress.com/advances-in-medical-education-and-practice-journal 